\title{
Evaluation of anti-proliferative and cytotoxic effects of chlorogenic acid on breast cancer cell lines by real-time, label-free and high-throughput screening
}

\author{
Onur Bender, Arzu Atalay* \\ Biotechnology Institute, Ankara University, Ankara, Turkey \\ * Correspondence: arzu.atalay@ankara.edu.tr (A.A.); Tel. +90-312-2225826 ext. 2503; fax. +90-312-2225826; ORCID No: \\ 0000-0003-1309-5291.
}

Received: 22 December 2017 / Revised: 2 February 2018 / Accepted: 12 February 2018

\begin{abstract}
Chlorogenic acid (CGA) is a major polyphenol in primary human diet, displaying a wide range of biological activities such as anti-oxidant, anti-inflammatory and anti-cancer effects. Several studies reported the chemopreventive effects of CGA on different types of cancers including breast cancer, which is the most common cancer among women worldwide. In this comprehensive study, we determined the anti-proliferative and cytotoxic effects of pure CGA on the phenotype of various breast cancer cell lines (MCF-7, SKBR-3, MDA-MB-231, MDA-MB-468 and BT20) with well-defined molecular classification and characteristics, in a time and dose dependent manner by using iCELLigence real-time and label-free cell analysis technology. Cells were plated on iCELLigence system-specific E-plate L8 and treated with CGA for 72 hours at concentrations ranging from $250 \mu \mathrm{M}$ to $8 \mathrm{mM}$. Obtained data were analyzed by RTCA data analysis software 1.0 and IC50 values of $952 \pm 32.5 \mu \mathrm{M}$ for MCF-7, $940 \pm 21.2 \mu \mathrm{M}$ for SKBR-3, 590.5 $\pm 10.6 \mu \mathrm{M}$ for MDA-MB-231, 882.5 $\pm 12.0 \mu \mathrm{M}$ for MDA-MB-468 and 1095 $\pm 121.6 \mu \mathrm{M}$ for BT-20 cell lines were calculated at the end of 72-hour assay. Based on our findings, CGA did not have cytotoxic activity on breast cancer cell lines, and IC50 values and growth curves displayed similar anti-proliferative patterns with slight variation.
\end{abstract}

KEYWORDS: Chlorogenic acid; phenolic compound; natural extract; breast cancer; proliferation; cytotoxicity; xCELLigence; RTCA.

\section{INTRODUCTION}

Natural products have health-beneficial effects through the many phytochemicals as their ingredients. By characterizing their phytochemical structures, a large number of bioactive constituents have been identified. The effects of these constituents on various diseases have been studied for many years and remarkable results have been obtained [1-2]. Functional foods in the primary human diet contain a wide variety of phytochemicals and their preclinical studies and clinical trials continue to increase intensively [3-8]. Russo et. al. summarized ongoing clinical trials of dietary phytochemicals on cancer prevention and therapy [9]. It appears that the use of the major phytochemicals, either solely, or in combination with other therapeutics, have effects on different types of cancers. In spite of all these developments, the therapeutic effects of the already identified chemicals are being analyzed for more effective drugs with fewer side effects. Besides, studies are underway for the discovery of new bioactive chemicals.

Chlorogenic acid (CGA) is a polyphenolic compound and it is the major constituent of many natural products, such as the coffee beans [10-11]. CGA, is also one of the most common components of the primary human diet, and has significant anti-oxidant, anti-inflammatory, anti-diabetic and anti-cancer effects due to its biological and pharmacological activity [12-15]. Focusing on cancer, several studies on different cancer types reported the chemopreventive effects and cell death mechanism regulation through CGA or natural extracts containing CGA [16-21]. However, the majority of these studies demonstrated the biological activity of CGA when applied within the total extract. Although natural extracts are beneficial to health and that this benefit comes from the major components of the product, it is not known whether this effect is due to the

How to cite this article: Bender O, Atalay A. Evaluation of anti-proliferative and cytotoxic effects of chlorogenic acid on breast cancer cell lines by real-time, label-free and high-throughput screening. Marmara Pharm J. 2018; 22 (2): 173-179. 
synergistic effects of the constituents or by another mechanism. Therefore, when evaluating a natural product, the phytochemicals must be isolated and comprehensive biological analyses must be carried out.

In vitro tests are important for shaping future studies in a more meaningful way, reducing the number of experimental animals and eliminating artifacts. Among them, proliferation and cytotoxicity assays are one of the pharmacological activity tests required to evaluate a component as a candidate drug. Each of the existing in vitro cell viability tests measures cellular events by different mechanisms [22-23]. According to these measurement results, anti-proliferative effect / cytotoxicity profiles are revealed. However, all conventional endpoint tests require additional markings on the cells or cellular fixation and this can lead to possible artifacts. Real-time cell analysis systems provide continuous viability measurements without additional marking of the cells by quantitative high-throughput measurements. Unlike conventional endpoint assays, continuous measurements can be taken from each well in the real time cell analysis system without any additional processing. For example, if a measurement is taken every 30 minutes in the standard 72-hour viability test, it is measured 144 times during this process, which allows real-time monitoring, and the results are calculated quantitatively [24-25].

This study aimed to investigate the anti-proliferative and cytotoxic properties of the chemically synthesized pure chlorogenic acid, by high-throughput, real-time and label-free monitoring on different breast cancer cell lines, which is the most common cancer among women.

\section{RESULTS AND DISCUSSION}

Phytochemicals have been one of the ideal agents to develop a common treatment protocol in cancer therapy. The first example was Paclitaxel, also known as Taxol, isolated from Taxus brevifolia barks in 1971, a chemotherapeutic agent that is being used in the clinic, which inhibits cell division. Another more cytotoxic chemotherapeutic agent, Docetaxel (Taxotere) was semi-synthesized from 10-diacetyl baccatin III which was isolated from European yew tree (Taxus baccata) leaf extracts. These nature-originating chemotherapeutic agents are being used in the clinic for treatment of certain cancer types, especially breast cancer [26-27].

Breast cancer is a highly heterogeneous disease with several subtypes, different immunological profiles and various tumor structure from patient to patient. Under these circumstances, different treatment strategies must be developed for each patient, since treatment options are limited, especially in advanced tumors. In particular, cases with no receptors, so-called triple negative breast cancers are more aggressive and have limited treatment options [28-31]. In addition to the current therapeutics, ongoing efforts focus on to develop less toxic and easier-to-obtain agents, with fewer side effects.

In this study, we performed a real-time and label-free high-throughput screening in order to analyze the effects of pure chlorogenic acid on breast cancer cell lines for the first time. As shown in Table 1, we have worked with five widely used breast cancer cell lines with different classifications and receptors types. We treated all the cells with 6 different doses of CGA in a time and dose dependent manner under the same conditions. We used 5\% DMSO and FBS-free DMEM as controls. We observed that 8,4 and $2 \mathrm{mM}$ CGA completely killed the cells in all of the cell lines tested (Figure 1). We also observed that $1 \mathrm{mM}$ CGA inhibited cellular growth of all cell lines except MDA-MB-231 (Figure 1, C). A slight induction of cellular growth was observed upon $1 \mathrm{mM}$ CGA treatment of MDA-MB-231 cells but around 50 hours, growth inhibition ratio pattern was similar to other cell lines. At 0.5 and $0.25 \mathrm{mM}$ doses, a slight inhibition was observed after 50 hours in the BT-20 cells (Figure 1, E), whereas in other cell lines the cells continued their normal growth. IC50 values were calculated with cell index values obtained at the 72-hour time point by RTCA software 1.0. IC50 values of $952 \pm 32.5 \mu \mathrm{M}$ for MCF-7, $940 \pm 21.2 \mu \mathrm{M}$ for SKBR-3, 590.5 $\pm 10.6 \mu \mathrm{M}$ for MDA-MB-231, 882.5 $\pm 12.0 \mu \mathrm{M}$ for MDAMB-468 and $1095 \pm 121.6 \mu \mathrm{M}$ for BT-20 cell lines were obtained (Table 2). According to these results, CGA was not cytotoxic on the breast cancer cell lines used in this study. However, although not satisfactory, CGA had variable anti-proliferative effects on different cell lines, as observed in Figure 1. When IC50 values and growth curves were evaluated, CGA had the most anti-proliferative effect on the MDA-MB-231 cell line $(\mathrm{IC} 50=590.5 \pm 10.6 \mu \mathrm{M})$ in concordance with the literature: Palmioli et. al. demonstrated that coffee extracts and its main component chlorogenic acid affects Ras proteins in MDA-MB-231 cells. They treated MDA-MB-231 cells with 25-500 $\mu \mathrm{M}$ pure CGA and observed $330 \mu \mathrm{M}$ CGA inhibited $50 \%$ of cell viability with RealTime-Glo ${ }^{\mathrm{TM}}$ MT (Promega, Madison, Wisconsin, USA) cell viability assay [17]. In another study, Mileo and colleagues investigated the therapeutic effects of artichoke and its polyphenols on breast cancer cell lines. The major phenolic acid in the artichoke extract was found to be chlorogenic acid. They observed cellular inhibition of MDA-MB-231 cell line due to elevated CGA concentrations (200 to $100 \mu \mathrm{M})$, which was tested by trypan blue 
exclusion method [32]. Further, to elucidate the anti-cancer mechanism of CGA in breast cancer with in vitro and in silico approaches, Deka et al., analyzed the cell viability-reducing effect of CGA on MCF-7 and MDAMB-231 cells by MTT assay and reported that CGA caused apoptosis-mediated cell-death in the MDA-MB-231 cell line. They also demonstrated that CGA caused morphological deformation in both cell lines, which we also have noticed [33]. Considering the results of these studies with our results, the effects of CGA on MDAMB-231 cells was being revealed through four different methods. Moreover, Suberu et al. reported that CGA inhibited cell growth of MCF-7 breast cancer cell line by using SRB test in a combinatorial study [34] Naso et al. observed no cytotoxicity following treatment of MDA-MB-231 and SK-BR-3 cells with $10 \mu \mathrm{MM}$ CGA [35]. Regarding all the results in the current literature, earlier studies with CGA have focused on the most popular model cell lines MCF-7 and MDA-MB-231. In our study, in addition to these two cell lines, different breast cancer cell lines were also included and the most effective result was obtained with an aggressive and difficultto-treat breast cancer type in the clinical phenotype, MDA-MB-231 cell line, consistent with the literature. Another unique aspect of our study is that CGA was not solubilized in toxic solvents such as ethanol and DMSO, but dissolved directly in serum-free cell culture medium. Thus, cells were not affected with an additional chemical treatment; they were directly exposed to the specific effect of pure CGA.

Our results indicate that CGA displayed time and dose dependent cell growth inhibitory effects on ER+, HER2+ and triple negative breast cancer cells. Since we have used real time cell analysis system, this work presents a more accurate assessment of the effects of natural products containing CGA as a major component, especially on breast cancer studies.

Table 1. Clinicopathological characteristics, classification and receptor profiles of breast cancer cell lines used in this study (adapted from 28-31).

\begin{tabular}{|c|c|c|c|c|c|c|c|}
\hline Cell line & $\begin{array}{l}\text { Age } \\
\text { (year) }\end{array}$ & Tumor Type & Source & Class & $\mathrm{ER}^{*}$ & $\mathbf{P R}^{*}$ & HER 2* \\
\hline MCF-7 & 69 & $\begin{array}{l}\text { Invasive ductal } \\
\text { carcinoma }\end{array}$ & Pleural effusion & Luminal & + & + & - \\
\hline SK-BR-3 & 43 & Adenocarcinoma & Pleural effusion & Luminal & - & - & + \\
\hline MDA-MB-231 & 51 & Adenocarcinoma & Pleural effusion & Claudin-low & - & - & - \\
\hline MDA-MB-468 & 51 & Adenocarcinoma & Pleural effusion & Basal A & - & - & - \\
\hline BT-20 & 74 & $\begin{array}{l}\text { Invasive ductal } \\
\text { carcinoma }\end{array}$ & Primary breast & Basal A & - & - & - \\
\hline
\end{tabular}

* $E R$, estrogen receptor; $P R$, progesterone receptor; $H E R 2$, human epidermal growth factor receptor 2

Table 2. IC50 values after CGA treatment of breast cancer cell lines included in the study.

\begin{tabular}{cc}
\hline Cell line & IC50 $(\mu \mathrm{M})$ \\
\hline MCF-7 & $952 \pm 32.5$ \\
SK-BR-3 & $940 \pm 21.2$ \\
MDA-MB-231 & $590.5 \pm 10.6$ \\
MDA-MB-468 & $882.5 \pm 12.0$ \\
BT-20 & $1095 \pm 121.6$ \\
\hline
\end{tabular}

\section{CONCLUSION}

Our results demonstrated that CGA did not have cytotoxic activity on breast cancer cell lines and growth curves displayed similar anti-proliferative patterns with slight variation. Based on our findings, future studies should aim to characterize cell death mechanisms by CGA, including healthy human breast cells, and revealing in vivo CGA-treated tumor activity. 

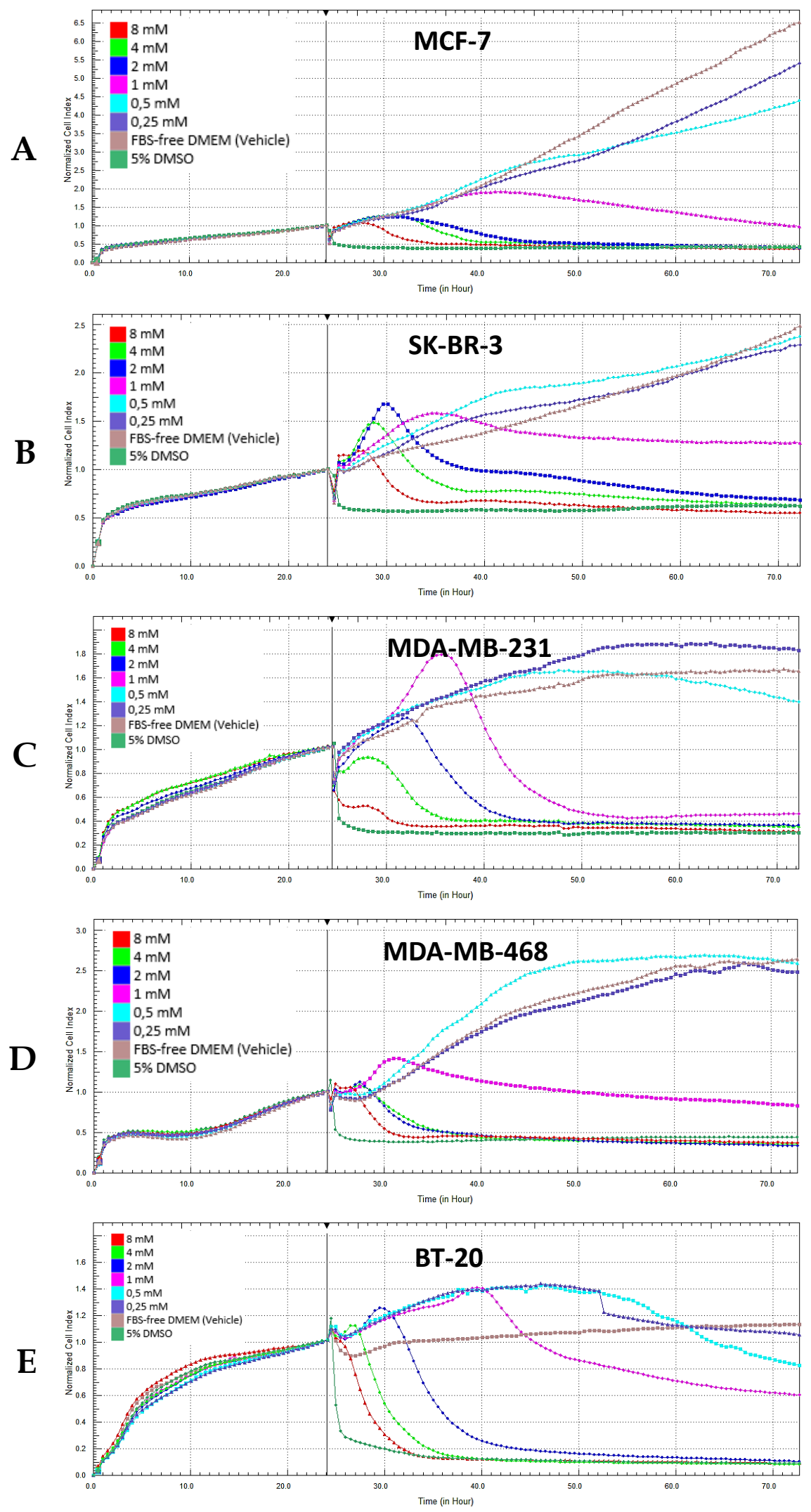

Figure 1. Representative time-and dose dependent effects of chlorogenic acid on different breast cancer cell lines by real-time monitoring. Cells were seeded on E-plate L8 and treated with various concentrations of chlorogenic acid for $72 \mathrm{~h}$. 5\% DMSO and FBS-free DMEM were used as controls.

A) MCF-7; B) SK-BR-3; C) MDA-MB-231; D) MDA-MB-468; E) BT-20 


\section{MATERIALS AND METHODS}

\subsection{Chemicals and Reagents}

Chlorogenic acid was purchased from Sigma, Cat: C3878 (St. Louis, USA). DMEM (Dulbecco's Modified Eagle's Medium) was purchased from Lonza (Basel, Switzerland). MEM Eagle with Earle's BSS (Minimum Essential Medium), McCoy's 5A medium, L-Glutamine, Penicillin/Streptomycin and Trypsin/EDTA were purchased from Biological Industries (Cromwell, CT, USA). FBS (Fetal Bovine Serum) was purchased from Biowest (Nuaillé, France). DMSO was purchased from Applichem (Darmstadt, Germany).

\subsection{Cell Lines and Culture}

MCF-7 (HTB-22), SK-BR-3 (HTB-30), MDA-MB-231 (HTB-26), MDA-MB-468 (HTB-132) and BT-20 (HTB19) human breast cancer cell lines were obtained from American Type Culture Collection (ATCC) (Rockville, Maryland, USA). MCF-7 and MDA-MB-231 cells were cultured in DMEM supplemented with 10\% heatinactivated FBS, $2 \mathrm{mM}$ L-glutamine, $100 \mathrm{U} / \mathrm{ml}$ penicillin, and $100 \mu \mathrm{g} / \mathrm{ml}$ streptomycin. BT-20 and MDA-MB468 cells were maintained in MEM Eagle with Earle's BSS containing 10\% heat-inactivated FBS, 2 mM Lglutamine, $100 \mathrm{U} / \mathrm{ml}$ penicillin and $100 \mu \mathrm{g} / \mathrm{ml}$ streptomycin. SK-BR-3 cells were maintained in McCoy's 5A medium with $10 \%$ heat-inactivated FBS, $2 \mathrm{mM}$ L-glutamine, $100 \mathrm{U} / \mathrm{ml}$ penicillin and $100 \mu \mathrm{g} / \mathrm{ml}$ streptomycin. All cell lines were cultured in a humidified atmosphere of $5 \% \mathrm{CO} 2$ at $37^{\circ} \mathrm{C}$. Cells were routinely cultured on T-75 flasks and at least 3-4 passages were performed before starting the cytotoxicity assays. Before each experiment, the cells were first washed with PBS (phosphate buffered saline), then trypsinized and counted by the trypan blue exclusion method with the use of a hemocytometer.

\subsection{Instrument}

The iCELLigence system is a compact version of xCELLigence real-time cell analysis systems (Acea Biosciences Inc., California, USA), which basically consists of 3 components; station, E-plate L8 and iPad, $(8$ (Apple Inc., California, USA). The iCELLigence station is placed into the standard cell culture incubator where the experiment takes place. The cellular events such as viability, cytotoxicity, morphological changes and growth kinetics are measured by gold microelectrodes which are located at the bottom of the E-plate L8. Cells are seeded on E-plate L8 as they are seeded on standard tissue culture plates and then placed on the iCELLigence station. The measured values are monitored in real time on the iPad® screen automatically via a Wi-Fi connection between the station and the iPad which allows the users to observe and analyze ongoing experiments. In addition to these hardware features, the system has its own software. This software not only allows the user to monitor the real-time results of experiments but also performs all analyses such as IC50, EC50 calculations.

\subsection{Analysis of Anti-Proliferative and Cytotoxic Effects of CGA with the iCELLigence System}

Anti-proliferative and cytotoxic effects of CGA on breast cancer cells were determined by using iCELLigence technology as we previously described [36-37]. Briefly, after adding $100 \mu$ l of growth medium to all wells, E-plate L8 was placed on the station and a short calibration measurement was taken. The plate was removed from the station and then seeded at $5 \times 10^{4}$ cells in a volume of $200 \mu$ l. The cells were incubated in the laminar cabinet for 30 minutes for the cells to settle down to the bottom of the E-plate before starting measurements. After incubation, the plate was reinserted into the station and the system was set to measure impedance every 30 minutes during 72 hours. After 24 hours of cell seeding, the assay was paused and the plates were transferred into the laminar cabinet. For treatment of cells 8, 4, 2, 1, 0.5 and 0.25 mM of CGA were added in $300 \mu \mathrm{l}$ growth medium. 5\% DMSO, which is known to be $100 \%$ toxic was used as a positive control during the assay. The plate was placed in the station again and the analysis was restarted. After completing a total of 72 hours of analysis, the data were analyzed with RTCA 1.0 software. IC50 values were calculated according to the values obtained from six doses.

Author contributions: Concept - O.B., A.A.; Design - O.B., A.A.; Supervision - A.A.; Resource - A.A.; Materials - A.A.; Data Collection \&/or Processing - O.B., A.A.; Analysis \&/or Interpretation - O.B., A.A.; Literature Search -O.B., A.A.; Writing - O.B., A.A.; Critical Reviews - A.A., O.B.

Conflict of interest statement: The authors declared no conflict of interest. 


\section{REFERENCES}

[1] Cragg GM, Newman DJ. Natural products: A continuing source of novel drug leads. Biochim Biophys Acta - Gen Subj. 2013; 1830: 3670-3695.

[2] Shen B. A new golden age of natural products drug discovery. Cell. 2015; 163:1297-1300.

[3] Surh YJ. Cancer chemoprevention with dietary phytochemicals Nat Rev Cancer. 2003; 3: 768-780.

[4] Yin SY, Yang NS, Lin TJ. Phytochemicals approach for developing cancer immunotherapeutics. Front Pharmacol. 2017; 8: 386.

[5] Costa C, Tsatsakis A, Mamoulakis C, Teodoro M, Briguglio G, Caruso E, Tsoukalas D, Margina D, Dardiotis E, Kouretas D, Fenga C. Current evidence on the effect of dietary polyphenols intake on chronic diseases. Food Chem Toxicol. 2017; 110: 286-299.

[6] Kaur V, Kumar M, Kumar A, Kaur K, Dhillon VS, Kaur S. Pharmacotherapeutic potential of phytochemicals: Implications in cancer chemoprevention and future perspectives. Biomed Pharmacother. 2017; 97: 564-586.

[7] Hosseini AG, Ghorbani A. Cancer therapy with phytochemicals: evidence from clinical studies. Avicenna J Phytomed. 2015; 5: 84-97.

[8] Maru GB, Hudlikar RR, Kumar G, Gandhi K, Mahimkar MB. Understanding the molecular mechanisms of cancer prevention by dietary phytochemicals: From experimental models to clinical trials. World J Biol Chem 2016; 7: 88-99.

[9] Russo M, Spagnuolo C, Tedesco I, Russo GL. Phytochemicals in cancer prevention and therapy: Truth or dare? Toxins. 2010; 2 :517-551.

[10] Farah A, Monteiro M, Donangelo CM, Lafay S. Chlorogenic acids from green coffee extract are highly bioavailable in humans. J Nutr. 2008; 138: 2309-2315.

[11] Stalmach A, Crozier A, Clifford MN, Williamson G. Phytochemicals in coffee and the bioavailability of chlorogenic acids. In: Crozier A, Ashihara H, Tomás-Barbéran F. (Eds). Teas, cocoa and coffee: Plant secondary metabolites and health. Wiley-Blackwell, Oxford, UK, 2011, pp. 143-168.

[12] Naveed M, Hejazi V, Abbas M, Kamboh AA, Khan GJ, Shumzaid M, Ahmad F, Babazadeh D, FangFang X, ModarresiGhazani F, WenHua L, XiaoHui Z. Chlorogenic acid (CGA): A pharmacological review and call for further research. Biomed Pharmacother. 2017; 97: 67-74.

[13] Hunyadi A, Martins A, Hsieh T-J, Seres A, Zupkó I. Chlorogenic acid and rutin play a major role in the in vivo antidiabetic activity of Morus alba leaf extract on type II diabetic rats. PLoS One. 2012; 7 (11): e50619.

[14] dos Santos MD, Almeida MC, Lopes NP, de Souza GE. Evaluation of the anti-inflammatory, analgesic and antipyretic activities of the natural polyphenol chlorogenic acid. Biol Pharm Bull. 2006; 29: 2236-2240.

[15] Cho AS, Jeon SM, Kim MJ, Yeo J, Seo KI, Choi MS, Lee MK. Chlorogenic acid exhibits anti-obesity property and improves lipid metabolism in high-fat diet-induced-obese mice. Food Chem. Toxicol. 2010; 48: 937-943.

[16] Yamagata K, Izawa Y, Onodera D, Tagami M. Chlorogenic acid regulates apoptosis and stem cell marker-related gene expression in A549 human lung cancer cells. Mol Cell Biochem. 2017 [Epub ahead of print].

[17] Palmioli A, Ciaramelli C, Tisi R, Spinelli M, De Sanctis G, Sacco E, Airoldi C. Natural compounds in cancer prevention: Effects of coffee extracts and their main polyphenolic component, 5-O-Caffeoylquinic acid, on oncogenic Ras proteins. Chem Asian J. 2017; 12: 2457-2466.

[18] Xue N, Zhou Q, Ji M, Jin J, Lai F, Chen J, Zhang M, Jia J, Yang H, Zhang J, Li W, Jiang J, Chen X. Chlorogenic acid inhibits glioblastoma growth through repolarizating macrophage from M2 to M1 phenotype. Sci Rep. $2017 ;$ 7:39011.

[19] Lee J, Kim YS, Lee J, Heo SC, Lee KL, Choi SW, Kim Y. Walnut phenolic extract and its bioactive compounds suppress colon cancer cell growth by regulating colon cancer stemness. Nutrients. 2016; 8 (7) pii: E439.

[20] Shao P, Zhang JF, Chen XX, Sun PL. Microwave-assisted extraction and purification of chlorogenic acid from byproducts of Eucommia Ulmoides Oliver and its potential anti-tumor activity. J Food Sci Technol. 2015; 52: $4925-4934$.

[21] Agar OT, Dikmen M, Ozturk N, Yilmaz MA, Temel H, Turkmenoglu FP. Comparative studies on phenolic composition, antioxidant, wound healing and cytotoxic activities of selected Achillea L. species growing in Turkey. Molecules. 2015; 20: 17976-18000. 
[22] Méry B, Guy JB, Vallard A, Espenel S, Ardail D, Rodriguez-Lafrasse C, Rancoule C, Magné N. In vitro cell death determination for drug discovery: A landscape review of real issues. J Cell Death 2017; 10:1179670717691251.

[23] Kepp O, Galluzzi L, Lipinski M, Yuan J, Kroemer G. Cell death assays for drug discovery. Nat Rev Drug Discov. $2011 ; 10: 221-237$

[24] Ke N, Wang X, Xu X, Abassi YA. The xCELLigence system for real-time and label-free monitoring of cell viability. Methods Mol Biol. 2011; 740: 33-43.

[25] Kho D, MacDonald C, Johnson R, Unsworth CP, O'Carroll SJ, du Mez E, Angel CE, Graham ES. Application of $\mathrm{xCELLigence} \mathrm{RTCA} \mathrm{biosensor} \mathrm{technology} \mathrm{for} \mathrm{revealing} \mathrm{the} \mathrm{profile} \mathrm{and} \mathrm{window} \mathrm{of} \mathrm{drug} \mathrm{responsiveness} \mathrm{in} \mathrm{real} \mathrm{time.}$ Biosensors. 2015; 5: 199-222.

[26] Singla AK, Garg A, Aggarwal D. Paclitaxel and its formulations. Int J Pharm. 2002; 235: 179-192.

[27] Mckeage K. Docetaxel: a review of its use for the first-line treatment of advanced castration-resistant prostate cancer. Drugs. 2012; 72: 1559-1577.

[28] Neve RM, Chin K, Fridlyand J, Yeh J, Baehner FL, Fevr T, Clark L, Bayani N, Coppe JP, Tong F, Speed T, Spellman PT, DeVries S, Lapuk A, Wang NJ, Kuo WL, Stilwell JL, Pinkel D, Albertson DG, Waldman FM, McCormick F, Dickson RB, Johnson MD, Lippman M, Ethier S, Gazdar A, Gray JW. A collection of breast cancer cell lines for the study of functionally distinct cancer subtypes. Cancer Cell. 2006; 10: 515-527.

[29] Shao W, Brown M. Advances in estrogen receptor biology: prospects for improvements in targeted breast cancer therapy. Breast Cancer Res. 2004; 6: 39-52.

[30] Holliday DL, Speirs V. Choosing the right cell line for breast cancer research. Breast Cancer Res. $2011 ; 13$ (4): 215.

[31] Burdall SE, Hanby AM, Lansdown MRJ, Speirs V. Breast cancer cell lines: friend or foe? Breast Cancer Res. 2003; 5(2): 89-95.

[32] Mileo AM, Di Venere D, Linsalata V, Fraioli R, Miccadei S. Artichoke polyphenols induce apoptosis and decrease the invasive potential of the human breast cancer cell line MDA-MB231. J Cell Physiol. 2012; 227: 3301-3309.

[33] Deka S, Gorai S, Manna D, Trivedi V. Evidence of PKC binding and translocation to explain the anticancer mechanism of chlorogenic acid in breast cancer cells. Curr Mol Med. 2017; 17: 79-89.

[34] Suberu JO, Romero-Canelón I, Sullivan N, Lapkin AA, Barker GC. Comparative cytotoxicity of artemisinin and cisplatin and their interactions with chlorogenic acids in MCF7 breast cancer cells. ChemMedChem. 2014; 9: 27912797.

[35] Naso LG, Valcarcel M, Roura-Ferrer M, Kortazar D, Salado C, Lezama L, Rojo T, González-Baró AC, Williams PA, Ferrer EG. Promising antioxidant and anticancer (human breast cancer) oxidovanadium(IV) complex of chlorogenic acid. Synthesis, characterization and spectroscopic examination on the transport mechanism with bovine serum albumin. J Inorg Biochem. 2014; 135: 86-99.

[36] Llorent-Martínez EJ, Zengin G, de Córdova MLF, Bender O, Atalay A, Ceylan R, Mollica A, Mocan A, Uysal S, Guler GO, Aktumsek A. Traditionally used Lathyrus species: Phytochemical composition, antioxidant activity, enzyme inhibitory properties, cytotoxic effects, and in silico studies of L. Czeczottianus and L. Nissolia. Front Pharmacol. 2017; 8:83.

[37] Picot MCN, Bender O, Atalay A, Zengin G, Loffredo L, Hadji-Minaglou F, Mahomoodally MF. Multiple pharmacological targets, cytotoxicity, and phytochemical profile of Aphloia theiformis (Vahl.) Benn. Biomed Pharmacother. 2017; 89: 342-350. 